\title{
Microzonation Analysis of Cohesionless and Cohesive Soil
}

\author{
Choy Soon Tan ${ }^{1, *}$, Yong Chang $\mathrm{Koh}^{1}$, and Aminaton Marto ${ }^{2}$ \\ ${ }^{1}$ Faculty of Engineering, UCSI University, 56000 Cheras, Kuala Lumpur, Malaysia \\ ${ }^{2}$ Faculty of Civil Engineering, Universiti Teknologi Malaysia, 81310 UTM Skudai, Malaysia
}

\begin{abstract}
Urban seismic risk is a continuous worldwide issue, numerous researchers are putting great effort in dealing with how to minimise the level of the threat. The only way to minimise the social and economic consequences caused but the seismic risk is through comprehensive earthquake scenario analysis such as ground response analysis. This paper intends to examine the characteristic of shear wave velocity and peak ground acceleration on cohesionless and cohesiveness soil. In order to examine the characteristic of shear wave velocity and peak ground acceleration on cohesionless and cohesiveness soil, ground response analysis was performed using Nonlinear Earthquake Site Response Analysis (NERA) and Equivalent-linear Earthquake Site Response Analysis (EERA). The value of ground acceleration was initially high at bedrock and vanishes during the propagation process. It is thus, the measured acceleration at surface is therefore much lower as compare to at bedrock. Result shows that seismic waves can travel faster in harder soil as compared to softer soil. Cohesive soil contributes more to the shaking amplification than cohesionless soil such as sand and harder soil. This is known as local site effect. The typical example is the Mexico Earthquake that happened in 1985. As conclusion, peak ground acceleration for cohesive soil is higher than in cohesionless soil.
\end{abstract}

\section{Introduction}

Urban seismic risk is a continuous worldwide issue, numerous researchers are putting great effort in dealing with how to minimise the level of the threat. Earthquake as a natural hazard is inevitable, more than billions of people throughout the world are subjected to this significant hazard. The only way to minimise the social and economic consequences caused but the seismic risk is through comprehensive earthquake scenario analysis such as ground response analysis. The occurrence of the earthquake is due to the release of seismic energy in the form of waveform from earth crust. The transmission of the wave form is largely depending on the density and elasticity. Figure 1 illustrates the seismic wave propagation from the epicentre to the local site. The seismic wave could be either amplified or deamplified depending on the local site effects which include soil type, soil density, thickness and etc [1]. Most researchers [2-4] found that the shear wave velocity (Vs) is higher when

* Corresponding author: cstan@ucsiuniversity.edu.my 
the density is higher. Ansal et al. [5] and Cox et al. [6] stated that the shear wave velocity in clay soil is lower as compared to as in sand. For the thickness of soil, researchers [7-10] stated that the shear wave velocity is increasing when the soil thickness is increased.

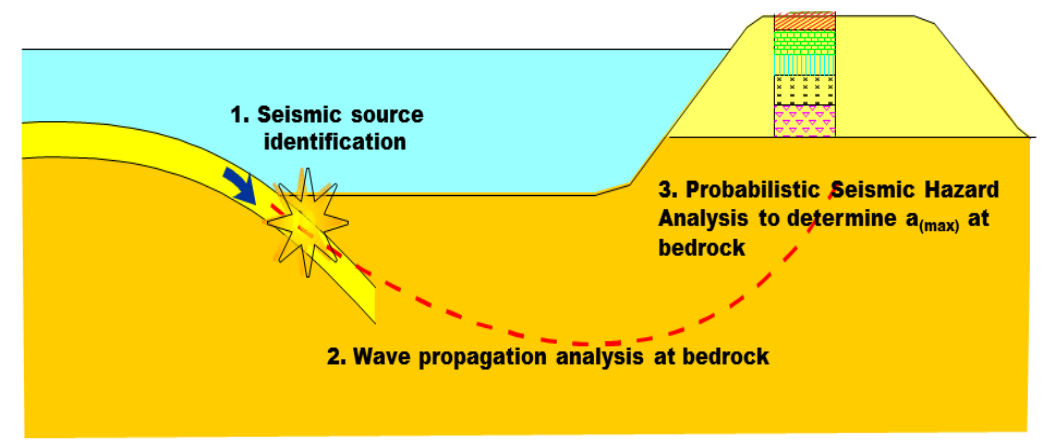

Fig. 1. Wave propagation from bedrock to surface. [11]

In general, studies have shown that there are two important geologic characteristics which affect the levels of ground shaking during an earthquake which are the softness of the ground, and the thickness of sediments above hard bedrock [12]. For the soil which is soft and thick, the shaking or amplification of the waves produced by an earthquake will be greater. This is because seismic waves can travel faster through hard rock as compared to softer soil. In soft soil, the waves slow down and their amplitude increases which then causes the shaking to be stronger. Thus, this paper intends to examine the characteristic of shear wave velocity and peak ground acceleration on cohesionless and cohesiveness soil.

\section{Methodology}

In order to examine the characteristic of shear wave velocity and peak ground acceleration on cohesionless and cohesiveness soil, ground response analysis was performed using Nonlinear Earthquake Site Response Analysis (NERA) and Equivalent-linear Earthquake Site Response Analysis (EERA).

There are two main input parameters was needed for the analysis which are the geotechnical data and earthquake data. The geotechnical data was extracted from the site investigation report. A total number of four site investigation reports to represent the soil condition of Johor Bahru were obtained. Altogether 25 borehole logs were used to represent the soil profile that consist mainly cohesionless soil (sand) and cohesive soil (clay). There are a few important information shall be extracted from the site investigation report and to be input to the NERA and EERA software. These inputs are includes Standard Penetration Blow Count (SPT-N), unit weight, soil thickness, soil type. Using correlation proposed by Bowles [5], the unit weigh for each soil layer was estimated. It is important to note that the software required the input of shear wave velocity, which was not included in the site investigation report. Thus, empirical formula that established by Marto et al $[13,14]$ that represent both type of cohesionless and cohesive soil was used, as follows:

$$
V_{\mathrm{s}}=77.13 \mathrm{~N}^{0.377}
$$

In which $\mathrm{Vs}=$ shear wave velocity

$\mathrm{N}=$ standard penetration count 
As the main interest of this work is on the characteristics of ground response parameters on different soil type, the default earthquake data was use in the analysis procedure. There are a few ground motion parameters could be obtained as the output of the software such as acceleration, amplification factor, Fourier spectrum, response spectrum and so on. However, the main output parameter that will be extracted for the comparison purposes in this study is the peak ground acceleration that calculated by the software. Acceleration is the rate of velocity change per unit of time while peak ground acceleration is the largest value of acceleration that will be recorded for a seismic event. In addition, the value of amplification was also been used for the comparison purpose. According to Kokusho [15], the amplification behaviour of the seismic wave that occurs between the ground surface and bedrock is depending on several factors such as soil layer, shear wave velocity, soil density and the damping characteristics of layer. In general, soft soil such as cohesive soil would amplify more as compare to cohesionless soil during the wave propagation process.

\section{Results and discussion}

This particular section summarised the analysis results. Table 1 and 2 show the example of the geotechnical data of two different site investigation report, mainly cohesive soil and cohesionless soil. It can be seen that the borehole in Table 1 consist mainly clay, which is cohesive soil while Table 2 consist mainly sand, which is cohesionless soil. Based on all these geotechnical data, the ground response analysis was carried out using NERA and EERA. The following subsection will summarise and discuss the ground response parameters such as shear wave velocity, peak ground acceleration and amplification obtained from the analysis. In addition, the comparison between the data obtained from NERA and EERA will be done.

Table 1. Typical geotechnical data of borehole at Taman Century.

\begin{tabular}{|c|l|c|c|c|c|}
\hline $\begin{array}{c}\text { Layer } \\
\text { Number }\end{array}$ & $\begin{array}{c}\text { Soil } \\
\text { Type }\end{array}$ & Thickness (m) & $\begin{array}{c}\text { Unit weight } \\
\left(\mathbf{k N} / \mathbf{m}^{\mathbf{3}}\right)\end{array}$ & Vs (m/sec) & $\begin{array}{c}\text { SPT-N } \\
\text { Value }\end{array}$ \\
\hline 1 & Sand & 1.5 & 14.14 & 77.13 & 1 \\
\hline 2 & Sand & 1.5 & 14.14 & 130.08 & 4 \\
\hline 3 & Clay & 1.5 & 17.28 & 116.71 & 3 \\
\hline 4 & Clay & 1.5 & 20.42 & 183.75 & 10 \\
\hline 5 & Clay & 1.5 & 20.42 & 202.85 & 13 \\
\hline 6 & Clay & 1.5 & 17.28 & 130.08 & 4 \\
\hline 7 & Clay & 1.5 & 17.28 & 116.71 & 3 \\
\hline 8 & Clay & 1.5 & 18.85 & 151.56 & 6 \\
\hline 9 & Clay & 1.5 & 18.85 & 141.49 & 5 \\
\hline 10 & Clay & 1.5 & 18.85 & 160.63 & 7 \\
\hline 11 & Clay & 1.5 & 20.42 & 176.59 & 9 \\
\hline 12 & Clay & 1.5 & 20.42 & 229.33 & 18 \\
\hline 13 & Clay & 1.5 & 20.42 & 238.62 & 20 \\
\hline 14 & Sand & 1.5 & 20.42 & 259.57 & 25 \\
\hline 15 & Sand & 1.5 & 20.42 & 303.95 & 38 \\
\hline 16 & Clay & 1.5 & 20.42 & 337.08 & 50 \\
\hline 17 & Clay & 1.5 & 20.42 & 337.08 & 50 \\
\hline 18 & Clay & 1.5 & 20.42 & 337.08 & 50 \\
\hline 19 & Clay & 1.5 & 20.42 & 337.08 & 50 \\
\hline
\end{tabular}


Table 2. Typical geotechnical data of borehole at Taman Bayu Puteri.

\begin{tabular}{|c|l|c|c|c|c|}
\hline $\begin{array}{c}\text { Layer } \\
\text { Number }\end{array}$ & $\begin{array}{c}\text { Soil } \\
\text { Type }\end{array}$ & Thickness (m) & $\begin{array}{c}\text { Unit weight } \\
\left(\mathbf{k N} / \mathbf{m}^{\mathbf{3}}\right)\end{array}$ & Vs (m/sec) & $\begin{array}{c}\text { SPT-N } \\
\text { Value }\end{array}$ \\
\hline 1 & Sand & 1.5 & 18.85 & 160.63 & 7 \\
\hline 2 & Sand & 1.5 & 17.28 & 100.16 & 2 \\
\hline 3 & Clay & 1.5 & 17.28 & 130.08 & 4 \\
\hline 4 & Clay & 1.5 & 18.85 & 77.13 & 1 \\
\hline 5 & Clay & 1.5 & 20.42 & 238.62 & 20 \\
\hline 6 & Clay & 1.5 & 20.42 & 183.75 & 10 \\
\hline 7 & Clay & 1.5 & 18.85 & 337.08 & 50 \\
\hline 8 & Sand & 1.5 & 18.85 & 337.08 & 50 \\
\hline 9 & Sand & 1.5 & 18.85 & 337.08 & 50 \\
\hline 10 & Sand & 1.5 & 18.85 & 337.08 & 50 \\
\hline 11 & Sand & 1.5 & 18.85 & 337.08 & 50 \\
\hline
\end{tabular}

\subsection{Shear wave velocity}

From Table 1 and 2, it can be seen that the increase of unit weight will increase the value of shear wave velocity. Fig. 2 shows an example of the unit weight and shear wave velocity for the same borehole. In general, the shear wave velocity is increased as the unit weight is increased. This is because as the unit weight is high, meaning the soil is in much compacted state, thus waves can travel faster within the particle. At the same time, the increase of SPT$\mathrm{N}$ value will also cause the increment of the shear wave velocity. This result was also been observed by Maheswari et al. [16]. By way of illustration from Table 1, layer 15 which has a blow counts of 38 achieved a lower shear wave velocity at $303.95 \mathrm{~m} / \mathrm{s}$ as to be compared to layer 16 which has a blow counts of 50 at $337.08 \mathrm{~m} / \mathrm{s}$ despite of both having the same unit weight of $20.42 \mathrm{kN} / \mathrm{m}^{3}$.

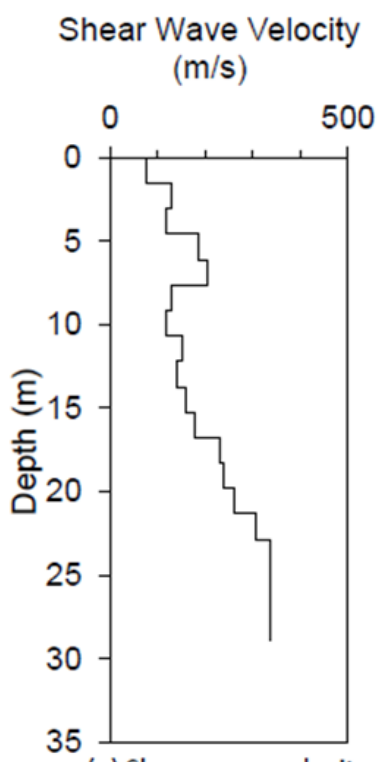

(a) Shear wave velocity

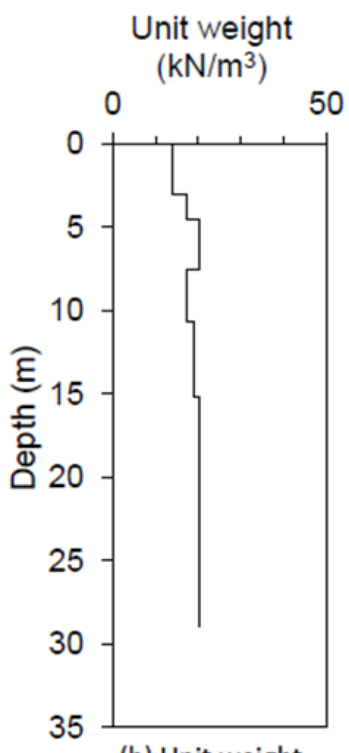

(b) Unit weight

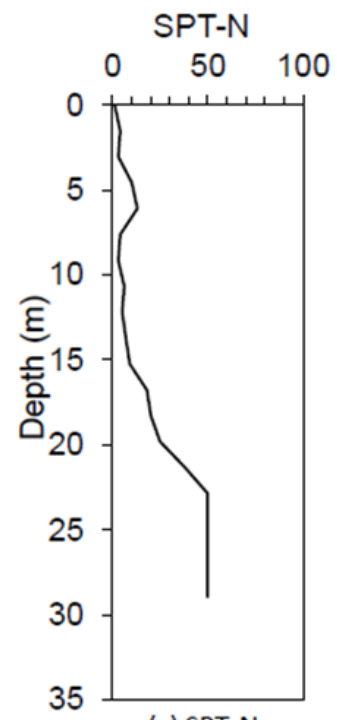

(c) SPT-N

Fig. 2. Value of unit weight and shear wave velocity of borehole at Taman Century. 


\subsection{Peak ground acceleration}

The bedrock acceleration and surface acceleration for all boreholes for all four projects' site investigation in Johor was examined through NERA. Table 3 summarised the range of ground and surface acceleration computed for each of the site investigation report obtained from NERA. From the table, it can be seen that the acceleration was reduced for all of the four sites. The value of ground acceleration was initially high at bedrock and vanishes during the propagation process. It is thus, the measured acceleration at surface is therefore much lower as compare to at bedrock.

Table 3. Results of peak ground acceleration.

\begin{tabular}{|c|c|c|}
\hline Project Site & $\begin{array}{c}\text { Range of bedrock } \\
\text { acceleration } \mathbf{( g )}\end{array}$ & $\begin{array}{c}\text { Range of surface } \\
\text { acceleration (g) }\end{array}$ \\
\hline Taman Century & $0.119-0.183$ & $0.053-0.061$ \\
\hline Tanjung Piai & $0.016-0.078$ & $0.013-0.056$ \\
\hline Indaputra & $0.0 .09-0.123$ & $0.052-0.071$ \\
\hline Taman Bayu Puteri & $0.119-0.183$ & $0.053-0.061$ \\
\hline
\end{tabular}

To look into more specifically, Table 4 summarised the value of acceleration for the site investigation report of Taman Century. From the table, it shows that the bedrock acceleration for the borehole 3 is dropped from $0.183 \mathrm{~g}$ to $0.056 \mathrm{~g}$ at surface. This is the highest drop among the five boreholes. On the other hand, borehole 5 has the lowest difference in acceleration which has the value of $0.061 \mathrm{~g}$. This is because seismic waves can travel faster in harder soil as compared to softer soil which is stated from Kumar [12]. In soft soil, the waves slow down and their amplitude increases which causes the shaking to be stronger. The borehole 3 consist mainly the cohesive soil (clay) while borehole 5 consist mainly sand which is cohesionless. In general, cohesionless soil is harder as compare to cohesive soil.

Table 4. Results of peak ground acceleration for Taman Century.

\begin{tabular}{|c|c|c|c|}
\hline $\begin{array}{c}\text { Borehole } \\
\text { No. }\end{array}$ & $\begin{array}{c}\text { Bedrock } \\
\text { Acceleration }(\mathbf{g})\end{array}$ & $\begin{array}{c}\text { Surface } \\
\text { Acceleration }(\mathbf{g})\end{array}$ & $\begin{array}{c}\text { Difference, } \boldsymbol{\Delta a} \\
\mathbf{( g )}\end{array}$ \\
\hline $\mathbf{1}$ & 0.158 & 0.057 & 0.101 \\
\hline $\mathbf{2}$ & 0.158 & 0.053 & 0.105 \\
\hline $\mathbf{3}$ & 0.183 & 0.056 & 0.127 \\
\hline $\mathbf{4}$ & 0.163 & 0.061 & 0.102 \\
\hline $\mathbf{5}$ & 0.119 & 0.058 & 0.061 \\
\hline
\end{tabular}

\subsection{Amplification factor}

The factor of amplification can be defined as the ratio between the peak horizontal acceleration at ground surface and the peak horizontal acceleration at bedrock. Table 5 summarised the range of amplification factor computed for each of the site investigation report obtained from NERA. In general, the higher the surface acceleration, higher the amplification factors the soil will be. The highest amplification factor can be observed for the site of Indaputra while the lowest is at Taman Century. For the range, Taman century have bigger range of the value for the amplification factor as compare to Indaputra. This is because the soil profile of Taman Century consist both cohesionless and cohesive soil. Indaputra site consist only the clay. Thus the range of amplification factor for Indaputra is relatively small as compared to Taman Century. However, it is at the highest value side of it. To explain this observation, Kamaruddin [17] stated that cohesive soil contributes more to the shaking amplification than cohesionless soil such as sand and harder soil. This is 
known as local site effect. The typical example is the Mexico Earthquake that happened in 1985 [1].

Table 5. Results of amplification factor.

\begin{tabular}{|c|c|}
\hline Project Site & Range of Amplification Factor, $\mathbf{A}_{\mathbf{F}}$ \\
\hline Taman Century & $0.134-0.691$ \\
\hline Tanjung Piai & $0.546-0.629$ \\
\hline Indaputra & $0.536-0.732$ \\
\hline Taman Bayu Puteri & $0.146-0.556$ \\
\hline
\end{tabular}

From Table 5, it can be seen that for this project, the range of the amplification factor is from $0.546 \mathrm{~g}$ to $0.629 \mathrm{~g}$. Also, from the table, it can be seen that borehole number 4 produces the highest amplification factor as the area while borehole number 2 produces the least amplification factor. Being said, a higher acceleration will cause the amplification factor to increase.

\subsection{Comparison between NERA and EERA}

In order to compare the difference between NERA and EERA, the site investigation report of Taman Century was selected for the analysis. Despite EERA and NERA are having similar system of the software under Microsoft Excel interface, the both software delivers a very similar but not entirely same results. It is necessary to get certain ground response parameters from the software in order to compare the frequency content on the investigated area and also to have a better understanding on the behaviour of the soil on the investigated area. Therefore, amplitude Fourier spectra and response spectra were plotted to observe the difference from both of the software.

\subsubsection{Amplitude fourier spectra}

Fig. 3 shows the Fourier spectra graph obtained through both NERA and EERA software. In the graph, it can be seen that the Fourier amplitude obtained through EERA is slightly higher as compared to the spectra obtained through NERA. Through EERA, it produced a value of Fourier amplitude of 0.0607 gs while NERA produced a value of Fourier amplitude of $0.0479 \mathrm{gs}$ where both achieved at the frequency of $1.46 \mathrm{~Hz}$.

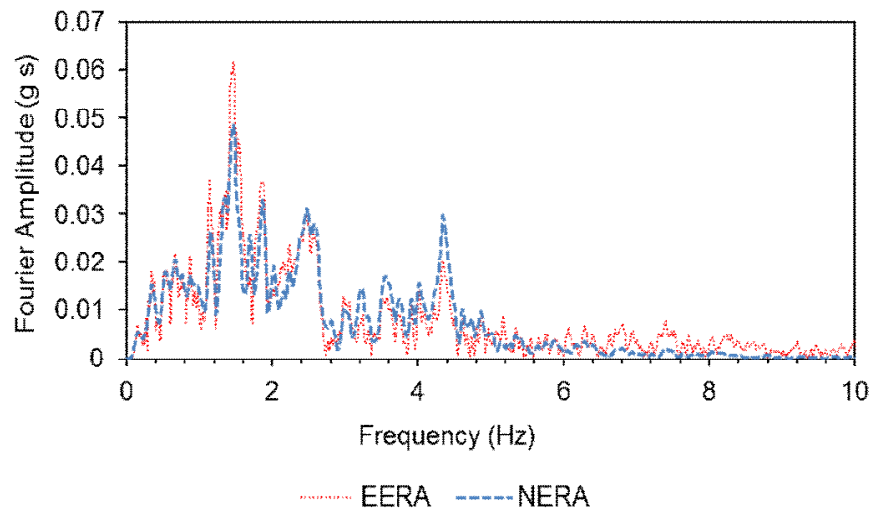

Fig. 3. Amplitude Fourier Spectra comparison from EERA and NERA software. 


\subsubsection{Response spectra}

By plotting a graph on the response spectra from NERA and EERA software, response spectra is measureable. Just like amplitude Fourier spectra, EERA software, too, achieved a generally higher value as compared to NERA software. From Fig. 4, it can be observed that EERA software obtained $0.48 \mathrm{~g}$ while NERA software obtained $0.36 \mathrm{~g}$ at the same period of time of $0.67 \mathrm{~s}$.

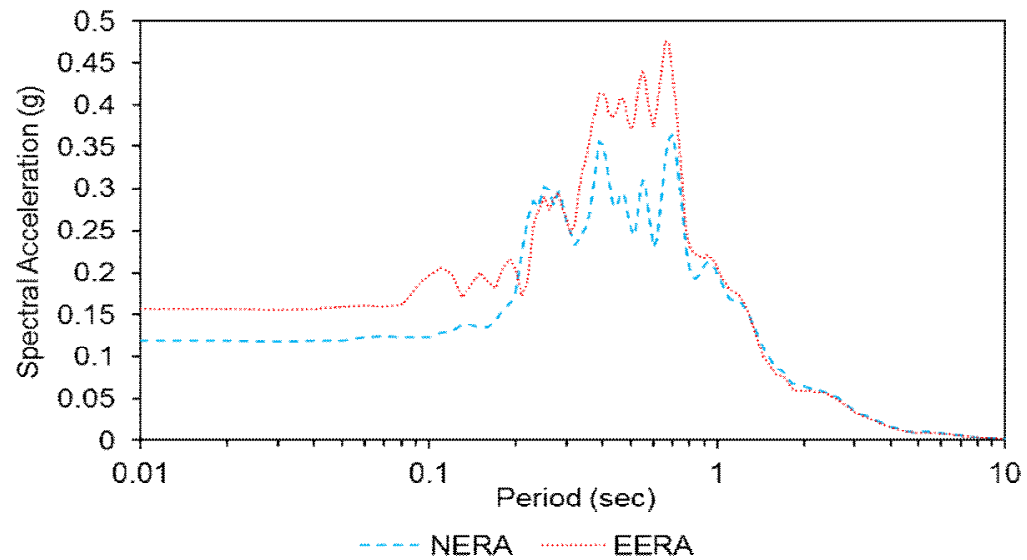

Fig. 4. Response spectra comparison from EERA and NERA software.

\section{Conclusion}

From the study, the following conclusions could be drawn which includes:

i) Shear wave velocity in cohesive soil is higher than cohesionless soil

ii) Seismic wave will be more amplified compared to cohesionless soil

iii) Peak ground acceleration for cohesive soil is higher than in cohesionless soil

The authors gratefully acknowledged the financial supports by the Ministry of Higher Education (MOHE) Malaysia, under the Fundamental Research Grant Scheme (UTM Vote No.: 4F849).

\section{References}

[1] S.L. Kramer, Geotechnical Earthquake Engineering, Prentice-Hall, New Jersey, USA (1996)

[2] A. Aksinenko, T. Hofstetter, V. Giller, A. Shvartsburg, D. Giller, I. Dan, M. Kalmanovich, Site effect and microzonation of the coastal plain from Northern Akko to Nahariyya for the Assessment of Earthquake Hazard, No. 533/545, 10 (2010)

[3] H.K.E.D. Moustafa, A.E.K.A. El-Aal, S. Salem, Microzonation of El-Fayoum, New City, Egypt, 64-83 (2013)

[4] P. Teves-Costa, I.M. Almeida, P.L. Silva, Microzonation of Lisbon: 1-D theoretical approach, 2579-2596 (2002)

[5] A. Ansal, G. Tönük, A. Kurtulucs, Microzonation for urban planning, 133-152 (2009)

[6] B.R. Cox, J. Bachhuber, E. Rathke, C.M. Wood, R. Dulberg, A. Kottke, S. M. Olson, Shear wave velocity and geology-based seismic microzonation of Port-au-Prince, Haiti, 27(S1), 67-92 (2011) 
[7] M.L. Sharma, J.P. Narayan, K.S. Rao, Seismic microzonation of Delhi region in India, 2043 (2004)

[8] M.S. Fnais, A.M. Al-Amri, K. Abdelrahman, Seismic microzonation and site effect response of Damman and Al Khobar cities in Eastern Saudi Arabia, 1-191 (2012)

[9] R. Motamed, A. Ghalandarzadeh, I. Tawhata, S.H. Tabatabaei, Seismic microzonation and damage assessment of Bam City, Southeastern Iran, 11(1), 110-132 (2007)

[10] Z. Wang, A technical note on seismic microzonation in the Central United States, 117(2), 749-756 (2008)

[11] M.A.Adnan, A. Hendriyawan, M. Irsyam, Microzonation maps for Kuala Lumpur and Putrajaya, Malaysian Journal of Civil Engineering, 23(1), 63-85 (2011)

[12] K. Kumar, Basic Geotechnical Earthquake Engineering, 49-61 (2008)

[13] A. Marto, C.S. Tan, F. Kasim, M. Suhatril, A correlation of shear wave velocity and standard penetration resistance, Electronic Journal of Geotechnical Engineering, 18, 463-471 (2013)

[14] A. Marto, C.S. Tan, T.K. Leong, Universal correlation of shear wave velocity and standard penetration resistance, Electronic Journal of Geotechnical Engineering, 18, 2727-2738 (2013)

[15] T. Kokusho, K. Sato, Site amplification formula for seismic zonation based on downhole array records during strong earthquakes, 12-17 (2008)

[16] R. Uma Maheswari, A. Boominathan, G.R. Dodagoudar, Use of surface waves in statistical correlations of shear wave velocity and penetration resistance of Chennai soils, Geotechnical and Geology Engineering, 28(2) ,119-137 (2010)

[17] A.F. Kamarudin, Development of microzonation map of southern industrial and logistic clusters, $80(2008)$ 